\title{
MRI detection of the activated region in the rat brain by Hochuekki-to, a traditional oriental medicine, and the related expression of BNIP-3 mRNA, a candidate of depression-related factor
}

\author{
Michihisa Tohda ${ }^{1,2 *}$ \\ ${ }^{1}$ Division of Medicinal Pharmacology, Institute of Natural Medicine, and \\ ${ }^{2}$ Wakan-yaku Theory-Based Integrated Pharmacology, Graduate School of Innovative Life Science, University of Toyama, Toyama 930-0194, Japan
}

\begin{abstract}
Japanese-Chinese traditional medicine (Wakan-yaku) contains various treatment prescriptions for the depression based on the peculiar theory, "mood, blood and water theory", "five elements theory" and others. I am studying to find treatment targets and therapeutic drugs of the depression by using the Wakan-yaku, mainly Hochuekki-to (HET). We have been reported that HET- and typical antidepressants-treatment enhance BINP-3 mRNA expression in cultured neuronal cell line, suggesting that BNIP-3 mRNA expression may be involved in depression. In this report, I found that 1) BNIP-3 mRNA was highly expressed in the hippocampus and the posterior hypothalamic neucleus in the rat brain by using the in-situ hybridization method and 2) HET stimulated the activity in the basal brain area at 15 min after oral administration by using MRI detection. Interestingly, the activated area is almost same as one of the expression region of BNIP-3. Although these results are in preliminary stage and further expression must be necessary, these results may suggest that HET rapidly stimulated the basal brain area probably through neuron from digestive system, and BNIP-3 may contribute in transduction mechanisms for anti-depressive effects of HET at that area.
\end{abstract}

\section{Introduction}

Wakan-yaku is based on Chinese traditional medicines, and of historical development has been achieved as Japanese traditional medicines. In present, many of Wakan-yaku extracted prescriptions are systematized perfectly in Japan and are listing in the "National Health Insurance drug price list in Japan" as authorized medicines. There is a lot of Wakan-yaku prescription which seems to be effective in functionality psychiatric disease, such as depression. It may be effective to use Wakan-yaku for studies about generation mechanisms of psychiatric disease and development of new medicines, since validities and safety are already established as crude drugs of authorized medicines in Japan.

Hochuekki-to (HET) is a typical Wakan-yaku prescriptions for acting on the mood deficits with inappetent. The first description of HET appeared in Chinese famous ancient document for medicine "Neiwaishang Bianhuolun", which was written by Dong Yuan Li in 1247. The expression of "hochu" in Japanese means improving the digestive system function and "ekki" means profiting for mood vigor. HET is standardized in Japan as combination of 10 kinds of crude drug (see material and methods), and No.41 is given as the common number among major pharmaceutical companies in Japan.

I and co-workers has been reported that HET has antidepressantlike effects in learned helplessness test in mice [1]. We also found that HET is involved serotonin 2C receptor (5-HT2CR) function and the mRNA expression [2] as well as antidepressants [2-4]. 5-HT2CR has been reportedly suggested the concerning with the neuronal development [5-7]. It has been also reported that HET- or typical antidepressants-treatment strongly enhanced BNIP-3 mRNA expression in cloned neuronal cells by experiments starting from the results of DNA array [8]. Furthermore, mRNA expression of various neuronal factors as well as BNIP-3 dynamically changes during the cultivation time in rat primary cultured neuronal cells, suggesting that these reflect the making of the neuronal function and the network [9].

In this report, the rat brain is used for experiments. The cloned and primary cultured cells were used as isolated system model of neuron in the brain in previous experiments, but it'll be important to consider an actual change in the brain. So, the distributions of BNIP-3 mRNA in the rat brain were studied by in situ hybridization method. As well as using the resting state MRI for small animal, influences of HET oral administration on the rat brain activities under medetomidinesedation condition were examined.

\section{Materials and methods}

\section{Extraction of HET}

The hot water extract of HET was made as previously reported [8]. HET is a combination of 10 galenicals. All galenicals were purchased

Correspondence to: Michihisa Tohda, Division of Medicinal Pharmacology, Institute of Natural Medicine, University of Toyama, Toyama 930-0194, Japan, Tel: +81-76-434-7611; Fax: +81-76-434-5056; E-mail: tohdam@inm.u-toyama.ac.jp

Key words: Wakan-yaku, depression, MRI for small animals, BNIP-3, mRNA expression

Received: March 18, 2018; Accepted: March 26, 2018; Published: March 31, 2018 
Tohda M (2018) MRI detection of the activated region in the rat brain by Hochuekki-to, a traditional oriental medicine, and the related expression of BNIP-3 mRNA, a candidate of depression-related factor

from Tochimoto Tenkai-do (Osaka, Japan). The daily dose of each galenical when HET uses in humans, the location where the plant source was grown, and the lot numbers are as follows: $4 \mathrm{~g}$ Ginseng Radix (Korea, No. 300190); 4 g Atractylodes Rhizoma (Zhejiang Sheng, China, No. 220295); 3 g Astragali Radix (Shan Xi Sheng, China, No. 100395); 3 g Angelicae Radix (Yamato, Japan, No. 120695); 2 g Citri Leiocarpae Exocarpium (Shikoku, Japan, No. 220894), 2 g Zizyphi Fructus (He Nan Zheng, China, No. 300395); 2 g Zingiberis Rhizoma (Yun Nan Sheng, China, No. 290788QC); 2 g Bupleuri Radix (Nara, Japan, No. 220290); 1.5 g Glycyrrhiza Radix (Xi Bei, China, No. 071194); and $1 \mathrm{~g}$ Cimicifugae Rhizoma (Ji Lin Sheng, China, No. 100288QC). A total of $98 \mathrm{~g}$ (4-fold of each) were combined and used for extraction with $900 \mathrm{ml}$ of boiling water for $60 \mathrm{~min}$. Galenicals were removed while the solution was still hot, and the extract was frozen to make freeze dried extract. The yield was $26 \%$.

\section{Animals}

Male Wistar rats (Japan SLC Inc., Hamamatsu, Japan) were housed in the laboratory animal room maintained at $25^{\circ} \mathrm{C}$ with $65 \%$ humidity on a $12 \mathrm{~h} \mathrm{light/dark} \mathrm{cycle.} \mathrm{Animals} \mathrm{were} \mathrm{given} \mathrm{food} \mathrm{and} \mathrm{water} \mathrm{ad}$ libitum. All experiments were conducted in accordance with Guiding Principles for Care and Use of Animals in the Field of Physiological Science of the Physiological Society of Japan.

\section{Three-dimensional high-performance liquid chromatography (3D-HPLC) analysis of extracts}

HET extract was filtered through membrane filter $(0.22 \mu \mathrm{m})$ and then submitted for HPLC analysis $(20 \mu \mathrm{l})$. The HPLC apparatus (Hitachi Ltd., Japan) consisted of a pump (L-2130) with analysis system software (Elite LaChrom); it was equipped with a photodiode array detector (UV 230-400 nm, L-2455), a system controller, an auto injector (L-2200), and a column oven (L-2300). The HPLC conditions were as follows: column, LaChrom Ultra C18 (5 $\mu \mathrm{m}$, Lot No. 21D5011; Hitachi Ltd., Japan) with $150 \times 4.6 \mathrm{~mm}$ I.D.; elutant, (A) $\mathrm{H}_{2} \mathrm{O}$ containing $0.1 \%$ formic acid and (B) $\mathrm{CH}_{3} \mathrm{CN}$ containing $0.1 \%$ formic acid (a linear gradient was used from ' $95 \% \mathrm{~A}$ and $5 \% \mathrm{~B}$ ' to ' $30 \% \mathrm{~A}$ and $70 \%$ B' for $90 \mathrm{~min}$ ); temperature, $20^{\circ} \mathrm{C}$; and flow rate $0.2 \mathrm{ml} / \mathrm{min}$.

\section{In Situ Hybridization Digoxigenin-labeled antisense}

To obtain the anti-BNIP-3 mRNA probe, the partial sequence of BNIP-3 cDNA for insert was isolated by RT-PCR methods from cDNA which made from rat brain total RNA by reverse transcription. The PCR mixture contained $1 \mu \mathrm{l}$ of RT product, $1 \mu \mathrm{M}$ of each primer, $1 \mathrm{mM}$ dNTPs, $2.5 \mathrm{mM} \mathrm{MgCl} 2$, and 2 units of Taq polymerase in the reaction buffer. The primer sequences are GAA CTG CAC TTC AGC AAT GG (forward) and GCC AGC AGA TGA GAC AGT AA (backward). The Annealing temperature is $57^{\circ} \mathrm{C}$. Obtained PCR product was treated by T4 DNA Polymerase to be smooth end followed by phosphorylation and ligated into the pBluescript vectors with smooth end which digested by SmaI. Anti-RNA probe was made using this insertcontaining pBluescript vector as a template. The vector has T3 and T7 primer reacting sites at both ends of the cloning site. From the fact that T7 RNA polymerase produced the antisense RNA probe in this experiment, the insert-containing vector was cut by HindIII to make the antisense probe.

The reactions to make the probe were performed using the digoxigenin (DIG)-conjugated UTP to label the probe. The incubation mixture contained HindIII-treated insert-containing vector as a template, $10 \mathrm{mM}$ dithiothreitol, $0.2 \mathrm{mg} / \mathrm{ml} \mathrm{BSA}, 1 \mathrm{mM}$ each of ATP, CTP and GTP, $0.65 \mathrm{mM}$ UTP with $0.35 \mu \mathrm{M}$ DIG-conjugated UTP and T7 RNA polymerase in $20 \mathrm{ml}$ of reaction buffer. After incubation for $60 \mathrm{~min}$ at $37^{\circ} \mathrm{C}$, the reaction mixtures were further incubated with $0.1 \mathrm{mg} / \mathrm{ml} \mathrm{DNase}$ I for $15 \mathrm{~min}$, and then ethanol precipitated in the presence of $0.4 \mathrm{M} \mathrm{LiCl}$ and $25 \mathrm{mM}$ EDTA. The resultant RNA probe labeled with DIG was further incubated in hydration buffer $(80 \mathrm{mM}$ $\mathrm{NaHCO}_{3}, 60 \mathrm{mM} \mathrm{Na}_{2} \mathrm{CO}_{3}, 6 \mathrm{mM}$ dithiothreitol) at $60^{\circ} \mathrm{C}$ to generate fragments of about $200-300 \mathrm{bp}$. The reaction was terminated by adding $0.3 \mathrm{M}$ sodium acetate and $0.25 \mathrm{mg}$ tRNA, and the product was precipitated with ethanol. The pellet was redissolved in sterile water. T3 RNA polymerase was similarly used to make the sense probe from the BamHI-digested insert-containing vector as a template.

To prepare histological sections, a non-treated rat was killed by decapitation, and the brain was removed, immediately frozen using powdered dry ice and stored at $-80^{\circ} \mathrm{C}$. Frozen brain was cut into sections $(16 \mu \mathrm{m})$ at $-18^{\circ} \mathrm{C}$, mounted onto gelatin-coated slides, and air-dried. Before hybridization, sections were fixed with $4 \%$ $(\mathrm{w} / \mathrm{v})$ paraformaldehyde in phosphate-buffered saline (PBS) for 15 min, treated with by $0.5 \mu \mathrm{g} / \mathrm{ml}$ proteinase $\mathrm{K}$, and acetylated. After prehybridization, the sections were hybridized overnight with DIGlabelled probe in hybridization buffer consisting of $5 \mathrm{X}$ standard saline citrate (SSC: $150 \mathrm{mM} \mathrm{NaCl}, 17 \mathrm{mM}$ sodium citrate, $\mathrm{pH} 7.0$ ), $50 \%$ formamide, $2.7 \mathrm{X}$ Denhardt's solution, $10 \mathrm{mM}$ EDTA, $20 \mathrm{mM}$ dithiothreitol, $0.25 \mathrm{mg} / \mathrm{ml}$ tRNA, and $10 \%$ dextran sulfate, at $55^{\circ} \mathrm{C}$. The hybridized sections were washed with $2 \mathrm{X} \mathrm{SSC}$ at $55^{\circ} \mathrm{C}$, treated with $50 \mu \mathrm{g} / \mathrm{ml}$ RNaseA for $30 \mathrm{~min}$, washed with $50 \%$ formamide $/ 2$ $\mathrm{X}$ SSC at room temperature, dehydrated in ethanol and dried. The digoxigenin-labeled probe hybridized with mRNA was detected immunohistochemically using an alkaline phosphatase-conjugated antidigoxigenin antibody with $450 \mu \mathrm{g} / \mathrm{ml}$ nitroblue tetrazolium and $175 \mathrm{mg} / \mathrm{ml} \mathrm{X-phosphate} \mathrm{as} \mathrm{coloring-reaction} \mathrm{substrates.}$

\section{MRI scanning in the rat brain}

The rat MRI scanning experiment under medetomidine sedation ( $0.3 \mathrm{mg} / \mathrm{kg}$ s.c.) was performed on a "4.7-T Unity Inova (Varian Inc.)" at the Yokohama Institute (Now on closedown) of BioView Inc under the company's conduction. HET $(1.0 \mathrm{~g} / \mathrm{kg}$ as estimated from the galenicals) was oral administered just before medetomidine treatment.

\section{Results}

The 3D-HPLC pattern of HET is shown in figure 1 . The analysis detected the following substances derived from the crude drug extract: chlorogenic acid from Angelicae Radix; hesperidin and narirutin from Citri Leiocarpae Exocarpium; [6]-gingerol from Zingiberis Rhizoma; liquiritin, isoliquiritin, apioliquiritin, apioisoliquiritin, and glycyrrhizic acid from Glycyrrhiza Radix; and 3-(3-hydroxy-4-methoxyphenyl)-2(E)-propenoic acid and ferulic acid from Cimicifugae Rhizoma. As expected under these conditions, substances originating from Ginseng Radix, Astragali Radix, Zizyphi Fructus, Atractylodes Rhizoma, Bupleuri Radix could not be detected by this 3D-HPLC. Other peak in the chart also could not be determined the content name.

The resting state MRI result of oral administration of HET in medetonidine-sedative rat brain is indicated in figure 2. The MRI signals were detected 15 and $60 \mathrm{~min}$ after administration of HET. The horizontal and coronal images are shown. Activation of the brain activity probably reflecting the rising of blood flow was observed around the deep side of backward of the brain at 15 min later of HET administration in horizontal section. In coronal section, almost same results were observed but activation signal in whole brain area was also seen by a place. These activation signals decreased at $60 \mathrm{~min}$, but the activation signals were still remained weakly. 
Tohda M (2018) MRI detection of the activated region in the rat brain by Hochuekki-to, a traditional oriental medicine, and the related expression of BNIP-3 mRNA, a candidate of depression-related factor

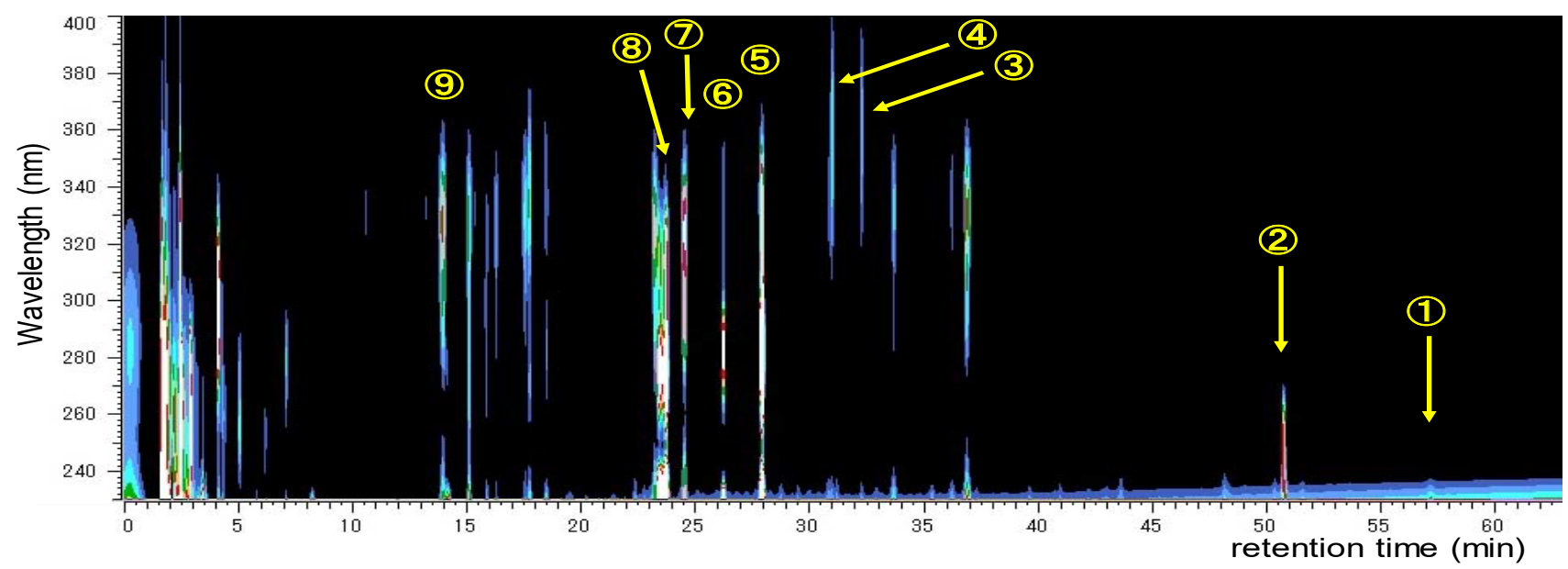

Figure 1. The 3D-HPLC pattern of HET.

HET extract ( $20 \mathrm{mg}$ by $20 \mathrm{~m} \mathrm{1}$ ) was submitted for HPLC analysis. The HPLC apparatus and the analysis conditions are described in "Materials and Methods". The identified contents with number in figure are follows: (1) [6]-gingerol, (2) glycyrrhizic acid, (3) isoliquiritin, (4) apioliquiritin, (5) hesperidin, (6) narirutin, (7) liquiritin, (8) 3-(3-hydroxy-4-methoxyphenyl)-2-(E)propenoic acid, and (9) chlorogenic acid. These contents are isolated from Zingiberis Rhizoma (1)), Glycyrrhiza Radix (ㄱ), (3), (4), (7)), Citri Leiocarpae Exocarpium (5), (6)), Cimicifugae Rhizoma (8) and Angelicae Radix (9). The components originating from Ginseng Radix, Astragali Radix, Atractylodes Rhizoma, Bupleuri Radix and Zizyphi Fructus were not identified under this condition. Other peak in the chart also could not be determined the content name.

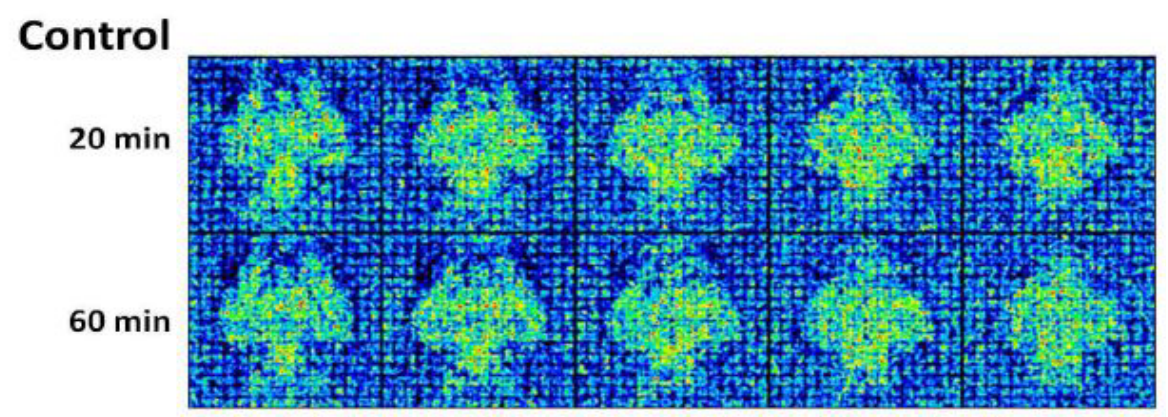

\section{$1 \mathrm{~g} / \mathrm{kg}$ Hochuekkito}

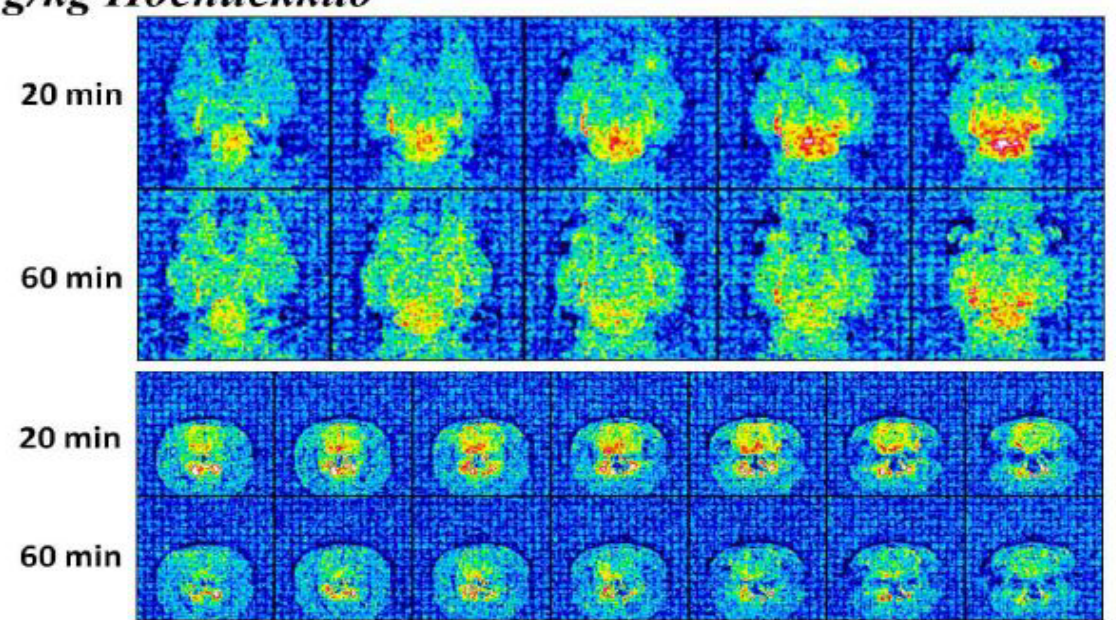

Figure 2. Identification of HET-responsive area in the rat brain by resting state MRI analysis.

HET stimulated the activity in the basal brain area at 15 min after administration. Interestingly, the activated area is almost same as one of expression region of BNIP-3 (Figure 3 ) which is a factor enhancing the expression by some antidepressant and HET. The enhancement of MRI signals by HET was rapid and transient, and almost recovered to the base level at 60 min.

It has been found that HET and antidepressant increases BNIP3 mRNA in cultivated nerve cells [8]. So, in this experiment, which region of the brain abundantly expressed BNIP-3 mRNA was detected in naive rat brain using the in-situ hybridization method. As a result, mRNA expression interestingly showed at high level in the depth site of the brain where the activation by HET was observed by MRI method.
Higher expression of BNIP-3 mRNA also observed in hippocampus especially in CA3 aria.

\section{Discussion}

The specially mentioned point of this article may be that MRI was used to study the effects of Wakan-yaku prescription in the brain, 


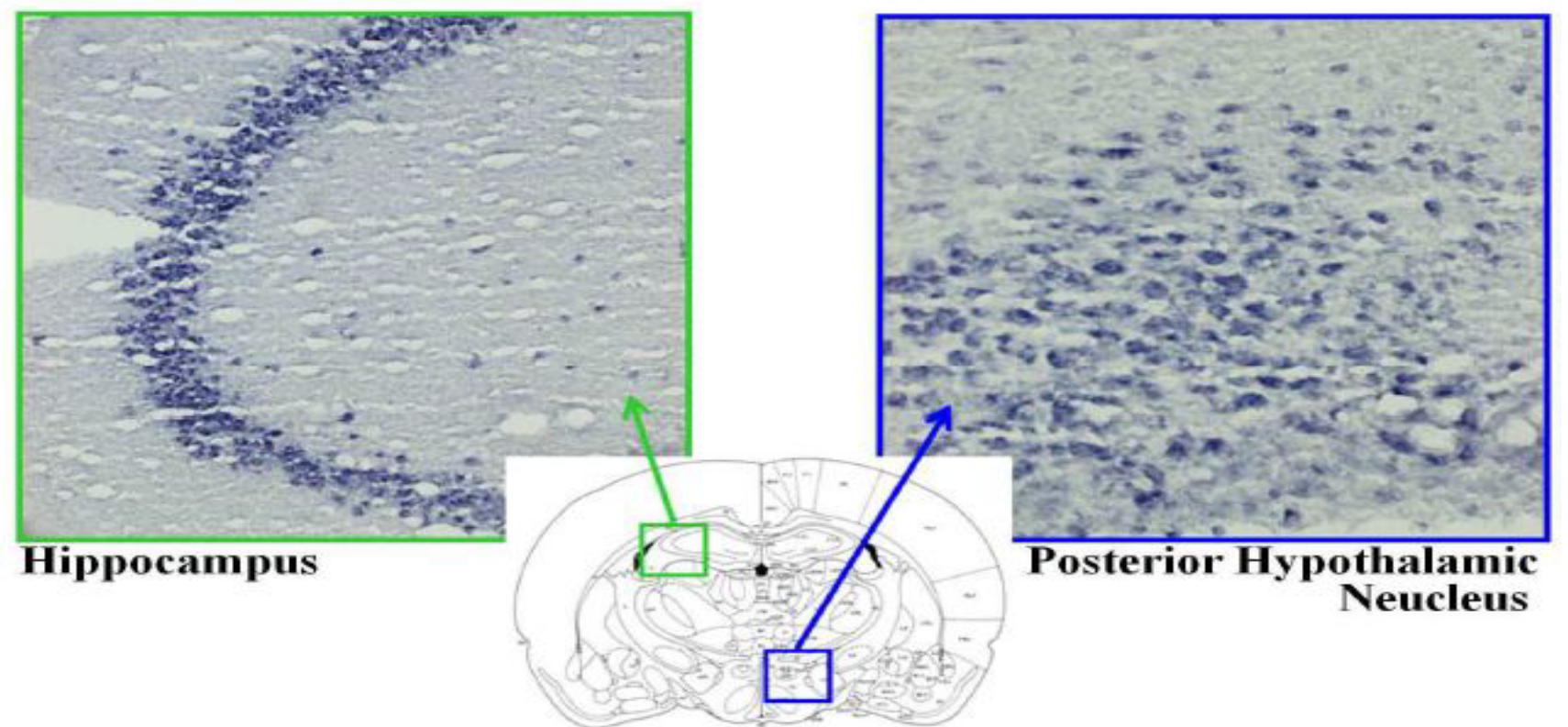

Figure 3. Identification of the BNIP-3 mRNA distribution in the brain by in situ hybridization methods with the digoxigenin-labeled antisense RNA probe BNIP-3 mRNA was highly expressed in the hippocampus and the posterior hypothalamic nucleus in the rat brain.

although the results were still in preliminary step. Since the rat brain was small, it was difficult to analyse the MRI signal using the software like SPM12. Advancing improvement of analysing way will give us remarkable knowledge about the Wakan-yaku effect in the future. This paper has a value as the herald. The constant expression of BNIP3 mRNA was also observed in the brain area of HET-activated. The author(s) previously reported that some antidepressants and HET enhance the BNIP-3 mRNA expression in cultured cells [8], although it did not study HET's effect in the rat brain. Further consideration is fascinating about the physiological roles of BNIP-3 in the brain region activated by HET and other antidepressants.

BNIP-3 is thought to have the function of mitochondrial cell death [10]. I have been reported, however, about the possibilities of other cellular functions, neurite extension and synaptogenesis [9]. Isolated primary cultured neuronal cell may reconstruct the neuronal function during the cultivation period with morphological changing and various mRNA expressions [5,9]. BNIP-3 may have a role for this reconstruction by expecting from the results of mRNA expression pattern. Since BNIP-3 mRNA has variant [9], the roles respective mRNAs will be also interested. In this report, abundant BNIP-3 mRNA expression was seen in the hippocampus and the brain stem where the neuronal activities are high in particular. Further detail studies for "BNIP-3 roles to the neuronal functions" and "the functional significance of the mRNA expression increase by antidepressants and HET" will lead to novel theories and discoveries.

MRI observation showed that the HET conspicuously activated the brain stem. This area includes raphe nucleus which has the function to release serotonin to the rest of the brain and central part of the HPA (hypothalamus-pituitary-adrenal gland) axis system which has the function to regulate the release of corticosterone as a stress hormone. HET seems to have some effort in these systems. Although it can't be shown as a dater, in experimental process, remarkable breathing restraint was observed just after administration of HET (1-2 minutes later). As it seems to be a synergistic effect with sedative action by medetomidine, the effect could be seen very rapidly. Because of the rapid response and HET's effort for digestive system, an ascending nerve system from stomach, not from adrenal, to hypothalamus may be involved in this HET-induce activation of the brain stem. Recently, studies using MRI method on depression and the mechanisms are increasing. There are many kinds of imaging reports about depression for examples; 1) the morphological study about the volumetric changes in the human brain area with major depressive disorder [11], 2) antidepressant effect on pain stimulus in depression patients compared with healthy control using the ultra-high field functional MRI methods [12], and 3) meta-analysis of functional and structural neuroimaging studies of pharmacological and psychological therapies [13]. Further detail examinations by MRI method about HET and other kinds of Wakan-yaku which have antidepressive effect are also interesting.

HET consists of ten kinds of crude drug. A Wakan-yaku prescription with crude drug constructions of resemblance to HET is Rikkunshito (RKT). RKT consists of eight kinds of crude drug, and six kinds are same as HET. RKT also acts on appetite increase as well as HET. Ghrelin, a peptide hormone released from stomach [14], is reportedly involved in the RKT's appetite effect [15]. Participation to serotonin in the brain has been also indicated as RKT's effect [15]. Although there are no reports about ghrelin secretion by HET till now as far as I know, comparative experiments about the action mechanisms of RKT and HET is future's interest because of similar effects to digestive system. Not only about appetite increase, but also various actions are reported as ghrelin effects for growth hormone stimulus [16], stomach movement control through vagus nerve [17], glucose metabolism [18] and others.

This article shows the effects of a Wakan-yaku prescription, HET, in the brain using MRI and the BNIP-3 mRNA expression region in the brain by using in situ hybridization to compare the MRI results. The result was still preliminary, but the fascinating knowledge in the future was obtained. There are many kinds of prescriptions acting on the psychiatric functional disorders, especially for depression, are included in Wakan-yaku. The detail analysis of Wakan-yaku by functional- or resting state-MRI methods will give us novel thinking and remarkable viewpoints about treatment of the psychiatric functional disorders. 
Tohda M (2018) MRI detection of the activated region in the rat brain by Hochuekki-to, a traditional oriental medicine, and the related expression of BNIP-3 mRNA, a candidate of depression-related factor

\section{Acknowledgement}

This work was supported by a Grant-in-Aid for Scientific Research (A) (\#21249047) from Japan Society for the Promotion of Science (JSPS).

\section{References}

1. Tohda M, Mingmalairak S. (2013) Evidence of Antidepressive Effects of a Wakanyaku, Hochuekkito, in Depression Model Mice with Learned-Helplessness Behavior. Evid Based Complement Alternat Med 2013: 319073. [Crossref]

2. Tohda M, Abdel-Fattah AFM, Nakamura S, Watanabe H. (2000) Effects of Hochuekki-to (Bu-Zhong-Yi-Qi-Tang), a Kampo medicine, on serotonin 2C subtype receptorevoked current response and the receptor mRNA expression. J. Traditional Medicines 17: 34-40.

3. Tohda M, Takasu T, Nomura Y (1989) Effects of antidepressants on serotonin-evoked current in Xenopus oocytes injected with rat brain mRNA. Eur J Pharmacol 166: 5763. [Crossref]

4. Sukma M, Tohda M, Watanabe H (2003) Chronic treatment of imipramine inhibited cell growth and enhanced 5-HT2C receptor mRNA expression in NG108-15 cells. $J$ Pharmacol Sci 92: 433-436. [Crossref]

5. Tohda M, Hang PNT, Matsumoto K (2009) Developmental changes in serotonin 2C receptor mRNA editing in the rat cerebral cortex and primary cultured cortical neurons. Biol Pharm Bull 32: 289-292. [Crossref]

6. Tohda M (2014) Serotonin $2 \mathrm{C}$ receptor as a superhero: diversities and talents in the RNA universe for editing, variant, small RNA and other expected functional RNAs. $J$ Pharmacol Sci 126: 321-328. [Crossref]

7. Tohda M (2018) Possible interaction of serotonin $2 \mathrm{C}$ receptor mRNA editing at C-site with expression of microtubule-associated protein 2 and neurite outgrowth in rat cultured cortical cells. MOJ Curr Res \& Rev. 1(1): 00004

8. Tohda M, Hayashi H, Sukma M, Tanaka K (2008) BNIP-3: a novel candidate for an intrinsic depression-related factor found in NG108-15 cells treated with Hochu-ekki-to, traditional oriental medicine, or typical antidepressants. Neurosci Res 62: 1-8. [Crossref]
9. Tohda M (2014) Changes in the expression of BNIP-3 and other neuronal factors during the cultivation period of primary cultured rat cerebral cortical neurons and an assessment of each factor's functions. Cell signalling and Trafficking 2:1.

10. Boyd JM, Malstrom S, Subramanian T, Venkatesh LK, Schaeper U, et al. (1994) Adenovirus E1B $19 \mathrm{kDa}$ and Bcl-2 proteins interact with a common set of cellular proteins. Cell 79: 341-35. [Crossref]

11. Matsuo K, Harada K, Fujita Y, Okamoto Y, Ota M, et al. (2016) Distinctive neuroanatomical substrates for depression in bipolar disorder versus major depressive disorder. Cereb Cortex 1-13. [Crossref]

12. Kraus C, Manfred Klöbl M, Tik M, Auer B, Vanicek T, et al. (2018) The pulvinar nucleus and antidepressant treatment: dynamic modeling of antidepressant response and remission with ultra-high field functional MRI. Mol Psychiatry. [Crossref]

13. Fu CH, Steiner H, Costafreda SG (2013) Predictive neural biomarkers of clinical response in depression: a meta-analysis of functional and structural neuroimaging studies of pharmacological and psychological therapies. Neurobiol Dis 52: 75-83. [Crossref]

14. Kojima M, Hosoda H, Date Y, Nakazato M, Matsuo H, et al. (1999) Ghrelin is a growthhormone-releasing acylated peptide from stomach. Nature 402: 656-660. [Crossref]

15. Takeda H, Sadakane C, Hattori T, Katsurada T, Ohkawara T, et al. (2008) Rikkunshito, an herbal medicine, suppresses cisplatin-induced anorexia in rats via 5-HT2 receptor antagonism. Gastroenterology. 134: 2004-13. [Crossref]

16. García-García F, Juárez-Aguilar E, Santiago-García J, Cardinali DP (2014) Ghrelin and its interactions with growth hormone, leptin and orexins: implications for the sleepwake cycle and metabolism. Sleep Med Rev 18(1):89-97. [Crossref]

17. Date Y (2012) Ghrelin and the vagus nerve. Methods Enzymol 514: 261-269. [Crossref]

18. Poher AL, Tschöp MH, Müller TD (2018) Ghrelin regulation of glucose metabolism. Peptides 100: 236-242. [Crossref]

Copyright: (C2018 Tohda M. This is an open-access article distributed under the terms of the Creative Commons Attribution License, which permits unrestricted use, distribution, and reproduction in any medium, provided the original author and source are credited. 